\title{
SEMIOTICS OF FASHIONSPEAK
}

\author{
Nina Khrystych, \\ $\mathrm{PhD}$ in Pedagogics, \\ Assistant Professor of Foreign Philology, Translation \\ and Applied Linguistics Department, \\ SHEI «Pereiaslav-Khmelnytskyi Hryhorii Skovoroda \\ State Pedagogical University», \\ Pereiaslav-Khmelnytskyi, Ukraine, \\ e-mail: forkaf@ukr.net
}

Received February, 11, 2019; Accepted June, 4, 2019

\begin{abstract}
The article is devoted to the semiotics of modern fashionspeak. The semiotic sign which creates image is studied in the article. The main idea is that forming and functioning of fashionspeak is based on linguistic theories. The author proves that fashionspeak holds symbolism having the capacity to express one's unique style, identity, profession, social status, and gender or group affiliation.

The author leads the idea that the connection between the text and fashion should be sought in the decoding of linguistic signs that creates differences between a male and a female fashion. The male fashionspeak is represented by using the words of the semantic field "strength" while the semantic field of female fashionspeak is "beauty". Hence, men's image is verbalized by the Nouns "strength", "power", "confidence", "reliability" etc. while women's image is verbalized by "pretty", "beautiful", "attractive", "awesome", "lovely", "gorgeous", "glamorous", "sexy", "chic", etc.

The author emphasizes that DRESS CODE concept does not include only "clothes" but also some external attributes of culture such accessories, perfumes, lifestyle, hairstyles, and so on. The axiological meaning in men's and women's DRESS CODE can easily increase an individual's selfsignificance by portraying the desirable values in accordance with their lifestyle. Therefore, the author believes that semiotics of clothes can be intentionally created.

Consideration is given to the international character of fashionspeak because of many international words (jeans, pullover, jumper, Dior, Prado, Versace) and the wide use of non-verbal means of communication.
\end{abstract}

Key words: fashion, fashionspeak, semiotics, semiotic sign, dress code, style, clothing, image.

\section{Introduction}

A semiotic resource in clothing is very specific for fashionspeak because of symbolism which convey the different messages. Clothing semiotics implies a lot of information about occupations, duties or obligations. Clothes reflect behavior and communicate prompts about social, marital and religious status.

We suggest that gender semiotics also communicate the male and female fashionspeak; the development of its genre systems; the verbal representation of relevent concepts (in our study it is STRENGHT concept for men and BEAUTY concept for women); the formation of new indications of linguistic personality and language picture of the world; the establishment of terminological system of fashion industry. Male fashionspeak presents a handsome men by the adjectives such as handsome, strong, rich, powerful, etc. The attributes of feminine beauty are mostly 
rated by the adjectives such as attractive, beautiful, gorgeous, glamorous, fashionable, pretty, sexy, lovely, etc.

Before we even speak to someone at a meeting, at a party, or in the street, our clothes express important information (or misinformation) about our occupation, origin, personality, opinions, and tastes. We pay close attention to how other people dress, though we may not be able to put our observations into words, we unconsciously register this information, so that when we communicate we already speak a universal language.

\section{Analysis of recent research and publications}

Semiotics as a science was formed only in the $20^{\text {th }}$ century, although the sign approaches to the study of certain phenomena and processes was found in the works of ancient and medieval scholars. This analysis continues the area of research initiated by the Swiss linguist Ferdinand de Saussure (1857-1913) who defined semiotics as "the science of the life of signs in society" (Joseph, 2016). Ferdinand de Saussure considered natural languages as sign systems in the framework of a new scientific discipline.

In 1938, Charles Morris (1901-1978) published the work "Fundamentals of the Theory of Signs", which became the first systematic presentation of semiotics as a science (Morris, 1938). Morris's semiotics is concerned with explaining the trirelation between syntactic, semantics, and pragmatics in a dyadic way, which is very different from the semiotics of Ch. Peirce (1839-1914). This caused some to argue that $\mathrm{Ch}$. Morris misinterpreted $\mathrm{Ch}$. Peirce by converting the interpretant into a logically existent thing.

The international linguistic interest in semiotics of fashionspeak is obvious. The American philosopher of fashion and closing, R. Rubinstein, studies the semiotic nature of clothing in verbal communication and names this process as "The Language of Clothes" (Rubinstein, 1998). Daniel Chandler, a semiotician, studied the fashion system and how ideologies are transmitted through dress (Chandler, 2007). E. Parker studies semiotics in fashion (Parker, 2014). T. Vasques, whose study is more connected with gender linguistics, suggests that a modern woman often has an androgynous look (Vasques, 2018).

Recently, the Ukrainian researchers have shown an increasing interest in fashionspeak. The present study draws primarily on the scientific work of G. Kovalenko whose paper is devoted to the research of contemporary fashion lexicon in the English language in cognitive and traditional lexicological aspects with regard to extralinguistic factors that influenced its formation (Kovalenko, 2005). The scientific works of A. Belova are devoted to the linguistic problems related to lexical semantics and intercultural stereotypes (Belova, 2002). The studies of L. Verba gave us an impulse to focus on morphological derivation of fashionspeak such as affixation, blending, combining, abbreviation, acronyms, telescopy, reduplication, etc. (Verba, 2003). O. Dmytruk asserts that stereotype is a way of manipulation of consciousness in mass media (Dmytruk, 2013).

The investigation of fashionspeak allows us to raise important issues about fashion as a social, cross-cultural and cross-linguistic phenomenon in the world of fashion because fashion itself includes social, cultural and linguistic trends. 


\section{Clothing and verbal signs}

The very first thing to note is that there are some potential terminological difficulties in studying fashionspeak. T. Short states that,

“ ... we appear to be saying that there are three elements of a sign. Strictly speaking, according to Ch. Peirce, we are interested in the signifying element, and it is not the sign as a whole that signifies. In speaking of the sign as the signifying element, then, he is more properly speaking of the sign refined to those elements most crucial to its functioning as a signifier. Ch. Peirce uses numerous terms for the signifying element including "sign', "semiotic object", and "interpretant". Here we shall refer to that element of the sign responsible for signification as the "sign-vehicle" (Short, 2007: 198).

An interesting idea of Ch. Peirce's studies is that he is keenly conscious of associating signs with cognition. In particular, Ch. Peirce claims that all thoughts are signs. We can see this from Ch. Peirce's early idea that every interpretant is itself a further sign of the signified object. Since interpretants are the interpreting thoughts we have of signifying relations, and these interpreting thoughts are themselves signs, it seems to be a straight-forward consequence that all thoughts are signs, or as Peirce calls them "thought-signs".

Charles Morris's development of a behavioral theory of signs - i.e., semiotics - is partly due to his desire to unify logical positivism with behavioral empiricism and pragmatism. Ch. Morris's union of these three philosophical perspectives eventuated in his claim that symbols have three types of relations: 1) to objects; 2) to persons; 3) to other symbols (Morris, 1971: 136). Later he called these relations "semantics", "pragmatics" and "syntactic". Viewing semiotics as a way to bridge philosophical outlooks, Ch. Morris grounded his sign theory in Mead's social behaviorism. In fact, Morris's interpretation of an interpretant, a term used in the semiotics of Ch. Peirce, has been understood to be strictly psychological. Ch. Morris's system of signs emphasizes the role of stimulus and response in the orientation, manipulation, and consummation phases of action. His mature semiotic theory is traced out in Signs, Language, and Behavior (Morris, 1946: 45).

Traditionally, men's fashion has been a neglected topic, with the consensus being that men don't care about fashion in the same way as women. However, sales projections say otherwise: the menswear market in the UK is set to grow by $0.7 \%$, while womenwear will shrink by $0.2 \%$, according to Fashion Magazine (Fashion. [magazine]).

Clothing that shows or portrays some kind of men's authority in society would fall in the first category. An example would be military uniforms for men, wigs used in English courts, or law enforcement uniforms. Through the ages men have been considered to be defenders, financial providers, career-focused, assertive and independent. Men's fashion is largely derived from military models, and changes in a European male silhouette were galvanized in theaters of European war where gentleman officers had opportunities to make notes of foreign styles such as the "Steinkirk" cravat or necktie.

Over time, men's style can be defined by the word "confidence" because practical outfit allows men to feel comfortable in smart attire. This is true as much in 
style as in any other art form - practice builds comfort. People who wear this kind of uniforms and emblems are expected by society to behave in certain ways. Not only that, but it is assumed that they possess certain economic, educational and social status.

Clothing that separates the sexes, and creates differences between a male and a female, would fall into the second category of clothing signs. Sex differences in clothing are due to "social judgments, personal evaluation and appropriate expectations of dress" (Rubinstein, 1998: 56). Because of these, the society has coercive power upon colors, shapes and fabrics in the clothes that men and women should wear. Examples of this include men wearing pants, while women are wearing skirts.

Within the third category one may find "seductive attire" as it was labeled by (Rubinstein, 1998: 58). However, wearing sex-specific clothing does not necessarily mean you will feel sensual or inclined to have sexual intercourse. Perhaps a better understanding of this could be derived from the church fathers. The seductive attire is not only a mixture of exposure and coverage of the body. A clothing piece one may use for reference is the décollegate, which was " ... first in use during the end of the Middle Ages" (ibid: 59).

Fashionspeak is common for different cultures and nations because of many international words (jeans, pullover, jumper, Dior, Prado, Versace) and the wide use of non-verbal means of communication. Nowadays, fashionspeak may originate with all levels of society by constantly creating neologisms and occasionalisms. The verbal part of fashionspeak touches the words referring to culture: clothes, shoes, accessories, lifestyle, entertainment, cars, perfumes, and so on but such nomination as style, dress and clothes are central semantic components of the notion "fashion" and often used in fashion definitions. Communication about fashion occupies a special place in the social and private life and involves a very large number of audience.

\section{The cognitive nature of fashionspeak}

An attempt to make the cognitive approach in the fashion world will help us to reveal the content and methods of linguistic objectification of fashionspeak, the relations between an author of the message and a reader. It is especially important to reveal the relation between the concept and the meaning of fashionspeak as it affects both the determination of the subject of cognitive linguistics and the development of methods for analyzing the semantics of fashionspeak. We presume that cognitive reception will show the interaction of cognitive and emotional processes that intersect with other expressive means.

The cognitive principles are determined by three general determinants of conceptual organization, namely human experience, perceptual selectivity, and cultural preference. The human experiences, derived from the anthropocentric view of world and our interaction with the world, lead to the following principles for choosing the means of expressions. It should be noted that most of the cognitive strategy aim at two main categories that have been applied in fashionspeak: verbal and visual. Visual strategies are emphasized and referred to presenting information iconically or graphically and in other concrete words to elicit mental imagery in the viewer. Presentation strategies are also very important and refer to techniques that provide a unifying framework for messages. Because the visual means are quick and 
easy to decode, you feel satisfied with the successful cognitive process which promotes the positive perception of the communication as a whole.

Cognitive reception of the fashion world shows the links between cognition and language. Research in cognition has shown that visual elements dominate over other elements connected with our way of understanding. We confirm that cognitive reception reflects the interaction of cognitive and emotional processes that intersect with perception. Fashionspeak correlates with fashion creativity and fashion vocabulary. The greatest challenge seems to be established in cultural, social, economic, political, religious, etc. conditions that may influence on the relevant conceptualization.

The cognitive principles are determined by three general determinants of conceptual organization, namely human experience, perceptual selectivity and cultural preference. The human experiences, derived from the anthropocentric view of world and our interaction with the world, lead to the following principles for choosing the means of expressions. It should be noted that most of the cognitive strategy aim at two main categories that have been applied in fashiospeak: verbal and visual. Visual strategies are emphasized and referred to presenting material information and in other concrete words to elicit mental imagery in the viewer. Presentation strategies are also very important and refer to techniques that provide a unifying framework for fashionspeak.

The linguistic investigation of cognition acquired a new shape due to the development of the cognitive theory, the central claim of which is that human conceptualization of experience. Consumers (especially women) choose the clothes according to their perception (what they can see, feel and touch). They often put the questions: (1) Is this dress fashionable? - Let us try it on! (2) Does my friend have the same dress? - No, it's impossible! I am the only person to wear this dress. But the reality of the situation is that there are a lot of other benefits that clothes cannot be felt by our senses and experience. There are subconscious elements: the deeper meanings and emotions the clothes awake, the more desire to wear them.

The item of fashion can arose the different emotions motivated by neural/hormonal systems, which can (1) give rise to affective experiences such as feelings of arousal, pleasure (love, surprise, sexual feelings / displeasure (fear, anger, egoistic feelings, disgust, perfectionism, narcissism; (2) generate cognitive processes such as emotionally relevant perceptual effects, appraisals, labeling processes; (3) activate widespread physiological adjustments to the arousing conditions; and (4) lead to behaviour that is often, but not always, expressive, goal-directed, and adaptive.

In short, emotion would be a set of changes including psychological arousal, affection and cognitive processes, which influence on choosing of clothes. The question of how these psychological, behavioural and cognitive phenomena coexist in the human experience of fashion. On the whole, we can confirm how close language, visualization and cognition are linked in fashionspeak.

\section{Dress code as a visual part of fashion nomination}

The semiotic system is formed by social interests and ideologies, so the fashion system is different. Semiotics is the study of signs and just as we can 
interpret signs and construct meaning from text we can also construct meaning from visual images such as fashion. Fashion is a language of signs that non-verbally converse meanings about individuals and groups. It plays a symbolic and communicative role, having the capacity to express one's unique style, identity, profession, social status, and gender or group affiliation.

In the modern society the ideologies in fashion are often implemented by celebrities or the dominant class. The meanings that are constructed through fashion largely depend on culturally accepted codes. This can be demonstrated in the choice of color for wedding ceremonies across different cultures. For example, a white dress is the traditional attire for a wedding ceremony in the western culture; however in the Asian culture the white color is associated with death and would be more appropriately worn at a funeral.

It is clear that semantic fields are open and interconnected. This fact is confirmed by the ambiguity of the words, which separate their values belong to different fields. For example, the word "dress code" has the meaning "a set of written and, more often, unwritten rules with regard to clothing." (Fashion-dictionary, Internet resource. Access : http://wwd.com/fashion-dictionary). This lexical unit can be replaced by synonyms: "dress rule", "dress traditions" as the meaning of term "dress code" may include indications of the person's gender, income, occupation and social class, political, ethnic and religious affiliation, attitude towards comfort, fashion, traditions, gender expression, marital status, sexual availability, and sexual orientation, etc.

Semiotic behavior of dress code has been developed since the $70 \mathrm{~s}$ of the $20^{\text {th }}$ century in the European and American culture. There was a concept of fashion business, an alternative teen fashion, club fashion, everyday fashion and even political fashion. Codes of clothing are material symbols which correspond to representations of the essence of symbol.

R. Rubinstein (Rubinstein, 1998: 66) has identified six distinct categories of dress in American society, upon which Dress Codes is based on clothing signs, clothing symbols, clothing tie-signs, clothing tie symbols, clothing fashion, clothing dress.

According to R. Rubinstein, there are three categories for clothing signs: "The first, is task oriented or instrumental in nature; the second, is having one primary meaning; and the third, is being recognized as a sign for those who wear it" (Rubinstein, 1998: 67). Dress Codes systematically analyzes the meaning and relevance of clothing culture. After ten years of teaching and research, R. Rubinstein has identified six distinct categories of dress, upon which Dress Codes is based. "Clothing signs" have only one meaning and are instituted by those in authority as required attire (police uniform, nun's attire); "clothing symbols", which have several meanings and involve individual choice (designer clothing, jewelry); "clothing tiesigns", which are specific types of clothing that indicate membership in a community outside mainstream culture (Hasidic, Amish, or Hare Krishna attire); "clothing tie-symbols", which act as a means of broader social affiliation emanating especially from fears, hopes, and dreams (Save the Earth clothing, Pro-Choice Tshirts, Madonna's crosses); "personal dress", which refers to the "I" component we bring in when dressing the public self (bowtie, dramatic, or artistic attire); and "contemporary fashion", which is the interaction between political and economic events and consumer sentiments, involving public memory 
Dress code is a non-verbal sign that can be interpreted differently depending on the context, situation or culture. It's in this way that the semiotics of fashion can be linked to social semiotics. According to Fred Davis,

"the chief difficulty of understanding fashion in its apparent vagaries is the lack of exact knowledge of the unconscious symbolisms attaching to forms, colors, textures, postures, and other expressive elements of a given cultures. The difficulty is increased by the fact that some of the expressive elements tend to have quite different symbolic references in different areas" (Davis, 1994).

Clothing signs were instituted by those in authority, have one meaning, indicate behavior, and are required attire (police uniforms, or the clothing of ministers and priests). Specific dress codes are identified by individuals within a culture and convey a message to help categorize and create meaning.

The various ways are employed in dress code, because a specific semiotic discourse has been developed for the realization of the best textile technology, and the effect can be achieved by connecting verbal and visual means. Only a little detail in clothes counts as a part of the whole picture. It is clear that clothes transmit social signals. Fashion can go beyond symbolizing a profession, an occupation or a taste. It can also communicate ideas about an individual personality, social status, or religious belonging. The dress code is not static, and as society and social interests change, so do trends and styles in dress.

Dress code is able "to decode" wealth and beauty, youth and health, leisure and position of a person. DRESS CODE concept does not include only "clothes" but also some external forms of culture such accessories, perfumes, lifestyle, hairstyles, and so on. Moreover, at the present stage of development of society, it turns out that fashion covers not only the above-mentioned spheres of human activities but also interferes in such fields as economics, industry, science and politics. Hence, we can say about student's dress code, doctor's dress code, politician's dress code and so on. In other words, dress code embraces not only clothing but also all spheres of human lives.

Let us study uniforms. A uniform is a specific type of clothing. It is worn to

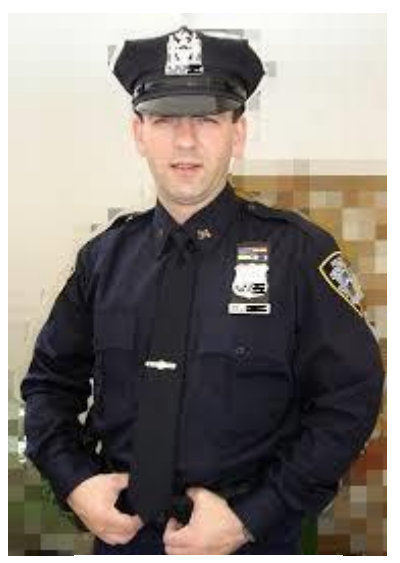

Figure 1 associate that person with an organization, trade or rank. Uniforms are symbolic and their meanings are arbitrary, in that they stand for their referent based upon agreement or habit of individuals within that culture.

The dress code is not static, and as society and social interests change, so do trends and styles. Fashion is a system of signs, whose meanings and significations are constantly shifting and changing depending on the time, place, and culture. Clothes and accessories are viewed as carrying non-verbal messages about social status, age, sex, interests, occupation, cultural and political preferences of their owner (the uniform of a police officer, doctor's white lab coats, etc.). 
Firstly, let us study the uniform of a police officer (see Fig. 1). In western society, a police officer typically wears variations of a blue suit and this generally symbolizes law, security, and authority.

White color of a doctor's coat (see Fig. 2) stands for cleanliness. Verbal names ascribed to these "signs" items of clothing and accessories function as interpretants - the third component in C. Peirce's sign theory that represents a link between the signifiee and the signifier.

"Contemporary fashion" reflects consumer

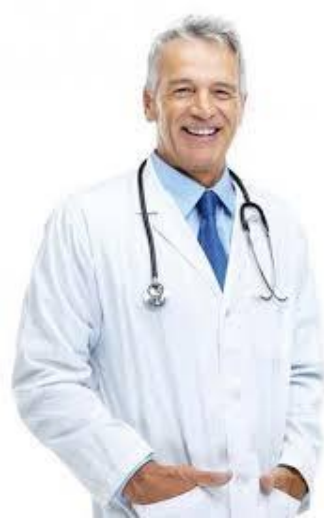

Figure 2

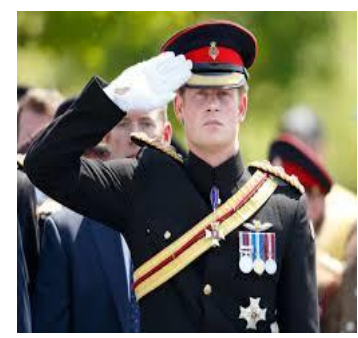

Figure 3 sentiments and the political and economic forces of the period. The description of aristocratic features of Prince Harry corresponds to the moral ideals of the beginning of the $21^{\text {st }}$ century and has a significant influence on the moral values and categories of moral consciousness, which may be relevant in any era and influenced the content of the moral standards: goodness, personal and family responsibilities, honor, nobility, dignity, courage, love, friendship, fairness, integrity, tolerance (see Fig. 3).

The given examples show us that fashionspeak is a kind of specific language which is used in business, best brands, companies and female and male communities. The aim of international cooperation is mainly to understand foreign culture, to be able to establish friendly relationships and to find common language with other nations.

In high fashion the meanings ascribed to clothes are verbalized by means of the collection and brand names (Gucci, Dior, Versace). Basic fashion trends of the $20^{\text {th }}$ century as well as the dress codes that developed by the end of the $20^{\text {th }}$ century - the beginning of the $21^{\text {st }}$ century are semantic by nature.

So, the objects of fashion have semantic nature that is reflected in language. We explored that style, dress and clothes are central semantic components of the notion "fashion" and have the most frequent use in fashion definitions. Finally, we can conclude that the more polysemiotic the clothing signs are, the higher influence is made on other people. The historical and cultural preferences are expressed on the material level by means of wearing certain clothes and accessories that are relevant to the concept of the signifier according to the sign theory. Hence, while speaking about dress code we should know the national tradition of fashion as well as fashion design, human civilization, and gender features. So, semiotics of dress code is highly readable and informative.

\section{Fashionspeak in male and female communities}

We should note that fashionspeak in male and female communities is different because of historical facts. Throughout history, there has been a separation between the gender roles and relationships that men and women play. These socially 
structured differences between men and women have contradicted each other at times. Fashionspeak has picked up on the tensions left by these contradictions as well. The symbolic separation of men and women is fundamental to the history of dress. From an early point in life, children learn to differentiate between a male and a female based on clothing and hairstyles. An example this may be attributed to television cartoons where superheroines are pictured with strong and muscular bodies. However, due to their clothing, they portray an image or an idea to the viewer of being sexy or attractive, therefore putting her physical strength as a secondary attribute. Let us compare these two pictures (see Fig. 4).

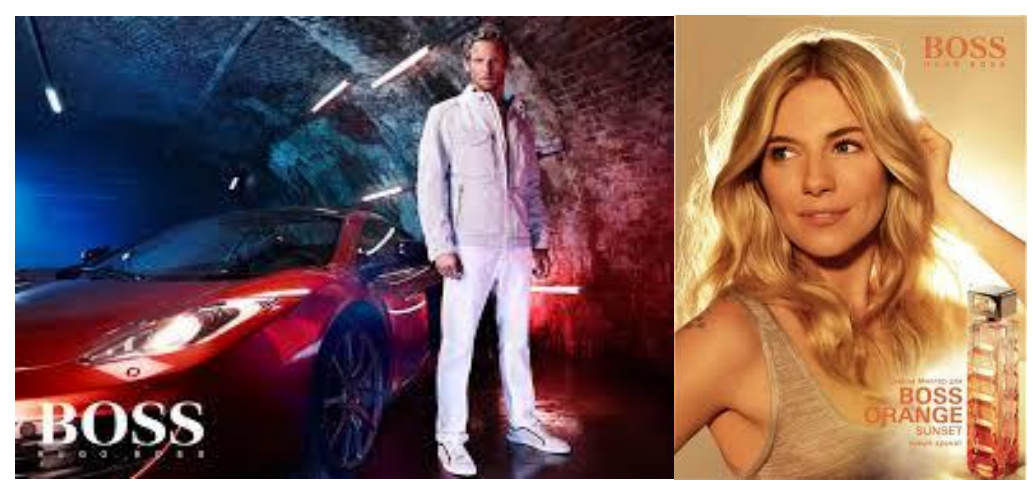

\section{Figure 4}

Figure 4 demonstrates a beautiful woman and a strong man. While seeing the attractive people, we do not need more words and further comments. Comparing these two pictures, we can notice that woman is characterized by a tendency to open and exaggerated expression of positive evaluation (non-verbal part) and the use of a wider range of evaluative adjectives (verbal part), while man is more restrictive in his manifestation. This fact reflects significant differences stereotypes of men and women. In modern English the sign "femininity" refers to the adjective "sexy" as well "masculinity' in male community also means "sexy". Practical studies on this issue can simulate the social and verbal portrait (stereotype) of a man and a woman in figurative and expressive forms. It reflects the ethical and socio-cultural values at a certain stage of social development.

BEAUTY is viewed as one of the basic concepts of feminine fashionspeak. The BEAUTY concept is regarded as a mental representation that can provide powerful insights into its meaning. The concept can be changeable and dependent on civilizational dimension of a particular historical era. Our investigation reveals the relations of the concept BEAUTY with other conceptual spheres such as NATURE, FEMALE BEAUTY and FASHION.

We should add that recently the magazines popularize so-called "unisex" which hides gender stereotypes. The words of basic man-female garments are jumper, sweeter, pullover, shirt, coat, suit, jeans, gloves, mittens, etc. The most popular, nonstereotypical commercial brands aim at most advanced men and women. A new trend of fashionspeak that it addresses to every age of people and with different kinds of figures (XS-6XL). It emphasizes natural beauty instead of perfect shapes.

Cultural values in men's wear can easily increase an individual's selfsignificance by portraying desirable values in accordance with their life style. This 
can be further explained by looking at or taking members of the European aristocracy as an example. They would wear clothes made with expensive fabrics and ornaments, which would differentiate them from the rest. All in efforts to show others that they possess a privileged place in a social class, where they could not be seen working in a field. Therefore, giving the impression of freedom and relaxation from harsh labor, unlike their servants.

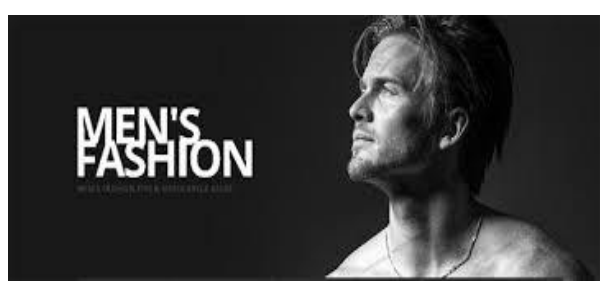

Figure 5

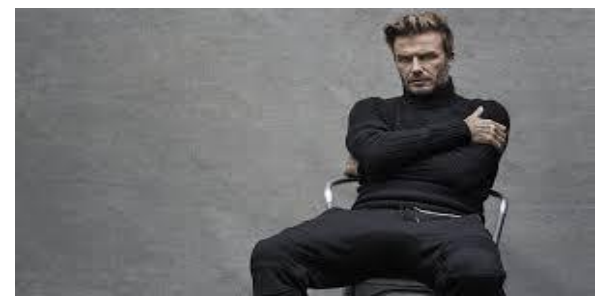

Figure 6

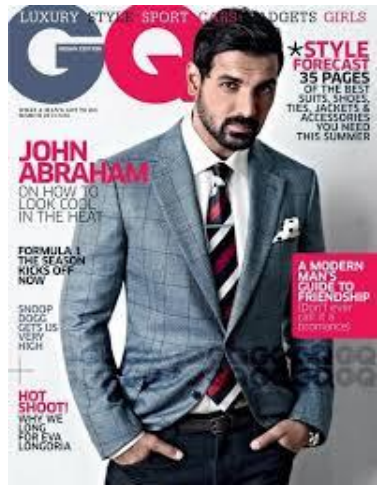

Figure 7

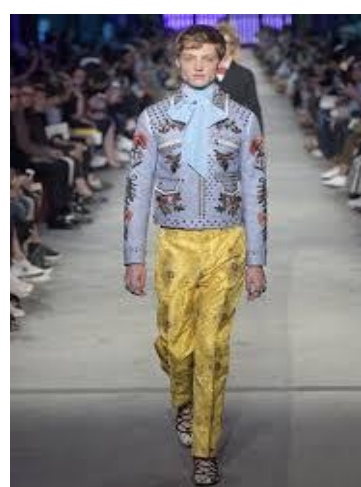

Figure 8
The semiotic sign is something that creates meaning. It can represent men's image that can be verbalized by the Nouns force, power, strength, willingness, confirmation, reliability etc. (see Fig. 5).

Some features of brutality denoting by the Nouns beard, goatee, moustache can also make a positive male picture. As an example, David Beckham illustrates this model (see Fig. 6).

Although, male sings are various. The model given below in "a chic jacket" can be characterized by the Adjectives athletic, successful, professional, seductive (see Fig. 7).

Accordingly, the words on the designation of such antivalues as sloppiness, wear, express a negative evaluation: a seedy jacket, a shabby look. Semiotic resources are constantly transformed. This theoretical stance presents people as sign-makers who shape and combine semiotic resources to reflect their interests. It is aligned with some sociological accounts of late modernity, highlights the potential for individual, social and cultural agency and change, and marks a shift away from conventional notions of grammar and lexicon which represented people as reproducing already-existing signs within a relatively stable and fixed system of choices.

Some men's styles blended the sensuality and expressiveness despite the conservative trend, the growing gay-rights movement and an emphasis on youth allowed for a new freedom to experiment with style, fabrics such as wool crepe, silk, nylon, etc., which had previously been associated with women's attire was used by designers when creating male clothing (see Fig. 8).

According to "Vogue", the readers of commercial magazines success entailed the popularization of non-heterosexist, anti-binarizing notions of gender and sexuality, the trumpeting of progressive political causes, and the representation of male experience in a high romantic and often 
decadent-aesthetic language. Nirvana and the band's grungy aesthetic stressed the likeness between the sexes, showing that men can cry over pain and wear babydoll dresses without having to put into question their sexuality (see Fig. 9).

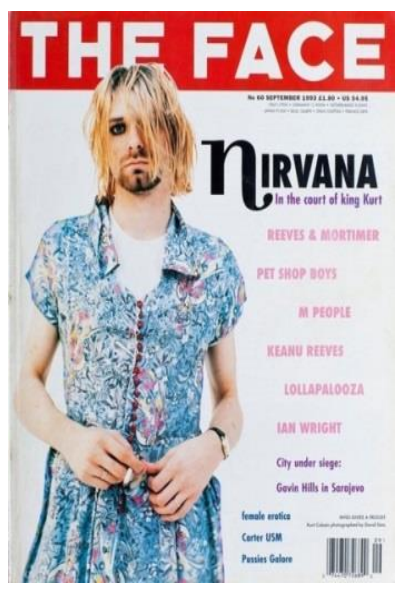

Figure 9

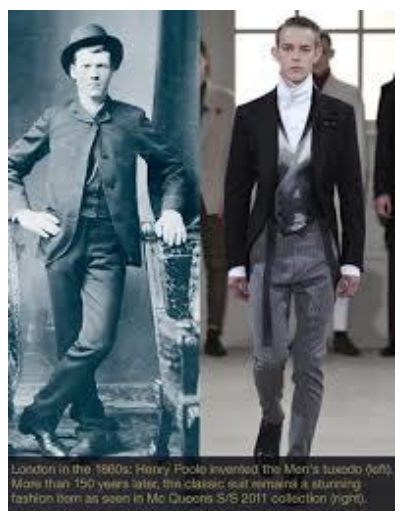

Figure 10

A feminine view in male fashion is becoming more prevalent in today's society and is often considered more fashionable than even the strongest man. We understand "the feminine view" as, the first, referring to physical feminine attributes; the second, having a psychological connotation and is a combination of both masculine and feminine traits; a kind of unified gender that defies social roles and psychological attributes.

The new words (neologisms) have appeared in fashionspeak. For example, "chinos" are cotton trousers inspired by the military; "cargo pants" are pants with pockets on the legs, designed to store bullets. More technically, the word "oxford" is way of constructing formal shoes and a cotton basketwear cloth used for shirts. Neologisms are a relatively recent or isolated term, word, or phrase that may be in the process of entering common use, but that has not yet been fully accepted into mainstream language. Neologisms of fashionspeak are often directly attributable to a specific brand, publication, period, or event. In the process of language formation, neologisms can develop their semantic fields. The word "tuxedo" belongs to archaisms (see Fig. 10).

The historical development of human clothing is inextricably linked with fashion (although it is far from limited), they are often identified. Fashion gives a sense of the present, a sense of time. Henry Pool (Great Britain, London) invented the men's tuxedo in 1860. (left). More than 150 years later the classic suit remains a stunning a fashion item Mc Queen's 2011 collection (right). The illustrations provide fascinating glimpses into the history of fashion and clothing.

Men's fashionspeak is marked by lexical units denoting clothing (shirts, sweatshirts, sweaters, jackets, coats, jeans, pants, shorts, suits, etc.); underwear (socks, sleep, lounge, T-Shirts, tanks), shoes (jazz shoe, jelly shoes, etc.), jewelry, watches, accessories (tie, cravat, pin, etc.). Clothes and accessories are viewed as carrying non-verbal messages about social status, age, sex, interests, occupation, cultural and political preferences of their owner.

Male fashionspeak as well as female fashionspeak is governed by social and cultural factors. They norms vary, depending on the gender, age, relative status, and cultural background of the individuals. In business, fashionspeak operates fashion terminology (fashion design, formal wear, business wear, casual wear). Everyday's speech is more likely to use slang (pampootie, peep-toe shoe) and neologisms (Oxford shoes, pointinini). 
Recently, the design of shoes has varied enormously through time and from culture to culture, with appearance originally being tied to functions. Additionally, fashion has often dictated many design elements, such as whether shoes have very high heels or flat ones. Contemporary footwear varies widely in style, complexity and cost. So, there are a lot of names of man's shoes: jutti, kitten heel, loafers, lotus shoes, mojari, moccasin, monk shoe, mule, opanak, opinga, organ shoes, Oxford shoes, pampootie, peep-toe shoe, peranakan, beaded slippers, peshawari chappal, platform shoe, pointed shoe, pointinini, rocker bottom shoe, ruby slippers, Russian boot, saddle shoe, sandal, slingback, slip-on shoe, slipper, sneaker, snow boot, spectator shoe, spool heel, steel-toe boot, stiletto heel, T-bar sandal, tiger-head shoes, toe shoe, turn shoe, venetian-style shoe, wedge, winklepicker, etc.

Fashionspeak has its gender peculiarities because of historical facts. The socially structured differences between men and women have contradicted each other at times. The symbolic separation of men and women is fundamental to the history of dress. As time has gone by, the forms of clothing (colors, fabrics and shapes) have changed, but the idea of gender difference has survived. However, due to their clothing, the feminine image is to be sexy and attractive, therefore putting her physical strength as a secondary attribute. A male image is represented by using the words of the semantic field 'strength' - strong, powerful, forceful, vulgar. The babystyle and feminine style are not widely accepted for men. To sum up, fashionspeak is based on linguistic theories.

\section{Conclusion}

The analysis of investigation of fashionspeak shows us that the study of a communicative structure of fashionspeak does not seem to be new or unusual in linguistics. The speaker builds up the fashionspeak message in which each element has its certain function the most important of which is a nominative function as in the given examples (a male style, a feminine style, etc.). Moreover, fashionspeak phenomenon in communicative paradigm is an interactive interpersonal communication, requiring linguistic and cultural skills. Thus, fashionspeak is an important part of public verbal communication for conveying semantic components of clothes, style, and dress.

After analyzing fashion in the cognitive paradigm, we can conclude that fashion represents a type of response to innovation, inherent in a significant number of people. It often manifests itself in the periodic change of objects of choice, as a new way of acting or thinking. We consider that fashionspeak is the result of human social and cultural activities. Fashionspeak is a person's desire for risk and renewal in speaking by using all layers of words (professionalisms, terms, archaisms, neologism, slang and so forth). That is why fashionspeak is more vivid and flexible than any other branch of life. We can see that the rapid change and the transformation of fashion pushes the global changes in fashionspeak.

We advocate the further research on study the mutual influence of world languages in the sphere of fashion, as well as on further research on stylistic, semiotic, rhetoric. We presume the semantic analysis of the specific vocabulary in the structure of fashion discourse as it needs the study of terminological units in general, and their variety - fashionspeak. 


\section{References}

Belova, Alla D. 2002. "Leksychna semantyka i mizkulturni stereotypy." In Movni i kontseptualni kartyny svitu. Kyiv: KNU imeni Tarasa Shevchenko.

Chandler, Daniel. 2007. Semiotics: The Basics. London: Routledge.

Davis, Fred. 1994. Fashion, Culture, and Identity. Chicago: The University of Chicago Press.

Dmytryk, Olha V.2013. "Stereotypy yak osnova dlia manipuliatsii svidomistiu." In Problemy semantyky slova, recehennia ta tekstu. Kyiv: KNU imeni Tarasa Shevchenko.

Dokashenko, Viktor M. 2008. "Linhvistychi aspekty movnoi komunikatsii." Materialy mizhnarodnoi konferentsii. Gorlivka.

Fashion. Access : https://www.google.com.ua/search? fashion+magazine

Fashion-dictionary. Access : http://wwd.com/fashion-dictionary

Joseph, John. 2016. Saussure. Oxford: Oxford University Press.

Kovalenko, Hanna M. 2005. Angliyska leksyka mody XX-XXI stolit. $\mathrm{PhD}$ diss. Kyiv: KNU imeni Tarasa Shevchenko.

Morris, Charles 1971. "Morris Foundations of the Theory of Signs." In International Encyclopedia of Unified Science 1:2. Chicago: University of Chicago Press.

Parker, Emily. 2014. Semiotics in Fashion. London: Routledge.

Rubinstein, Ruth. 1998. The Language of Clothes. London: Routledge.

Vasques, T. 2018. "A Look at Modern Day Androgynous Women." Access : https://www.everydayhealth.com/healthy-living/look-modern-day-androgynous-women/

Verba, Lidiya G. 2003. Porivnyalna leksykolohiya anhliiskoi ta ukrainskoi mov. Vinytsa : Nova knyha.

Short, Thomas. 2007. Semiosis and Intentionality. Transactions of Charles Sanders Peirce Society. Cambridge: Cambridge University Press. 